$\xi=1$ 国

\title{
Use of saturated green material in vaporic thermal atmosphere to absorb ions have negative impact
}

\author{
Abbas Ali Mahmood Karwi ${ }^{1 *}$, Eman Mohammed Abdullah ${ }^{1}$ \\ ${ }^{I}$ Al furat Al-Awsat Technology University, Babylon Technology Institute - Iraq \\ *Corresponding author E-mail: abbas30032002@Yhoo.com
}

\begin{abstract}
This design has been used to adsorb ions from industrial water of companies and factories. Our system has three integrated phases used to test efficiency of an unspecified number of residues of food as adsorbed materials. In this system, we adsorb copper and cobalt ions, these ions are available with high rates in Al Musayab thermal station, high concentration of these ions pose a threat to the health of the population. In general, the presence of these ions in the proportions set by the World Health Organization, namely, $(1 \mathrm{mg} / \mathrm{L})$ are very useful for the com-pletion of the metabolic processes of the living cell, but a greater focus for this will lead to tremendous health risks. Testing processes a proved that there is an exact match between empirical and theoretical testes of (Freundlich and Langmuir) models. Through the mathematical analysis of the trial data under different thermal conditions, all testes proved that green algae powder is the best filtered material, because its high adsorption efficiency which equal to $(77 \%)$ with Gips free energy equal to $(-39 \mathrm{~kJ} / \mathrm{mol})$, followed by Pulp date powder has proven to be excellent efficiency $(75 \%)$ with enthalpy equals to $(-12 \mathrm{~kJ} / \mathrm{mol})$. In general, all food remnants have been selected to be test in our adsorp-tion system, this system has high capacity to adsorb various ionic roots of industrial water of AlMusayab thermal station. All Adsorbents have thermal coefficient falls between one and zero (one $<\mathrm{RL}<0$ ), this value represents the perfect choice of adsorption to be tested on this system. The total system cost is $(\$ 10000)$.
\end{abstract}

Keywords: Ions; Thermal; Free Energy; Efficiency; Capacity.

\section{Introduction}

Surface area of the active carbon in nature characterized by nonpolar, but through the extraction and production processes are interacting with oxygen, which leads to the production of many effective and specific sites and can give polar vulnerable feature on the product of carbon substance. Because of natural activation, the carbon can be used widely in the treatment of ores using aqueous solutions to extract gold, silver, and other metals. Therefore, the most important industrial processes for the production of active carbon with high capacity and large sizes is the use of potassium hydroxide. Accordingly, the adsorption process is a process that is used to isolate the heavy metals from aqueous solutions, so there are many studies about the types of materials, which absorb ions of different metals from aqueous their solutions. Biomass of organic matter has proved that it has good ability to isolate and reduce the concentration of heavy metals from the aquatic environment; also, there are many studies, which have shown the ability of bacterial cell walls, fungi and algae on linking the heavy ions and attach it to their content of organic. The use of dead biomass to remove heavy metals from aqueous solution has been studied extensively in recent years. Also it proves that the plant cell walls which differ in their composition and characteristics according to the type of great importance plant cell to remove these ions from their solutions because of the a substance of the polymeric substance, which may lead to the effective surface activity. The most important of these is the rice bran fiber as one of the wastes, this rice bran is a by-product of milling process, and this material is very cheap, costing about ( $\$ 1$ for each $\$ 50$ ) of the cost of the activated carbon material. There are two theories are essential to describe the relationship between the concentrations of metals before and after treatment processes, these theories are Langmuir and Freundlisch. Other researchers studied the effect of the active carbon manufactured from coconut charcoal to remove phenol from water of industrial plants, they found very good response, also found very congruence and compatibility between theoretical calculations using theories of Langmuir and Freundlisch and the results obtained.

\section{Materials and methods}

The researcher designed a bioreactor for conducting the process of interaction between the green leaf algae, available in abundance of the rivers, salt lakes and ciprofloxacin material. The interacting processes took place with the hot steam supplied by attached tank supplied by a tank with the hole diameter not exceed than $(5 \mathrm{~mm})$ filled with water and equipped with the severe a heating system steam supplied to tank from the top down. The tank supplied with closed keys. The water in tank stay period of time not less than $(10$ minutes), then filtering the water and pumped after measuring the flow rate to table food wastes filters, table is equipped with a whole system of keys to control the flow rate to each filter. Through this table, we can test the effectiveness of the hundreds of food wastes to demonstrate their ability to adsorption of free radicals and so we can utilize waste intended as one of the environmental waste for use in industrial purposes. We are tested (6 types) of food wastes like; powder of anguish palms, tea waste, coal powder, palm leaves, husks of peanuts, sunflower husks, peel of egg powder. System and adsorption materials in addition to tanks 
of Al- Musyyab industrial water are see in Fig.1(a,b). The schemat-

No. 1 (in closed)0.

ic representation for system of adsorption materials is in diagram

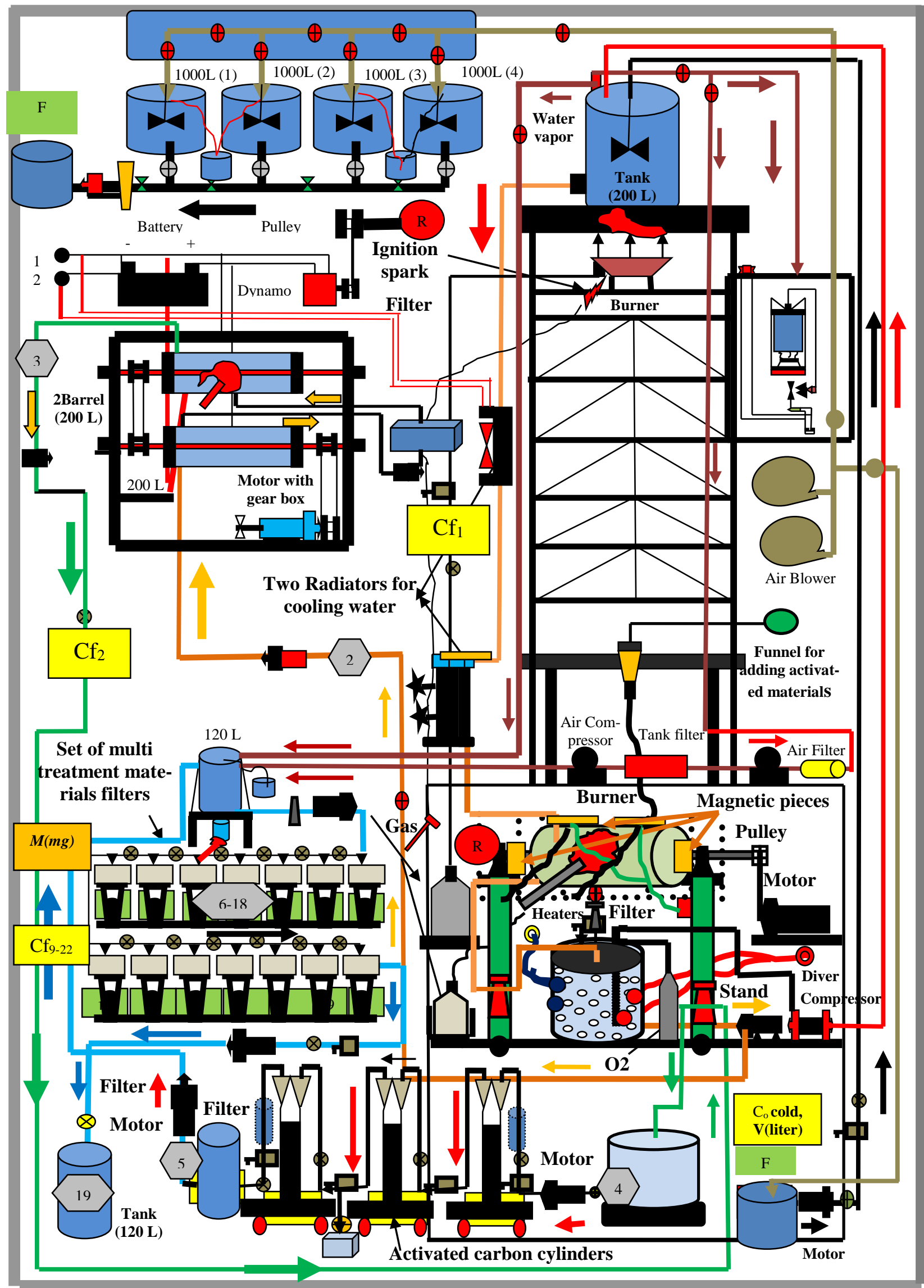

Diagram 1: Schematic Representation for System of Adsorption Materi-Als 


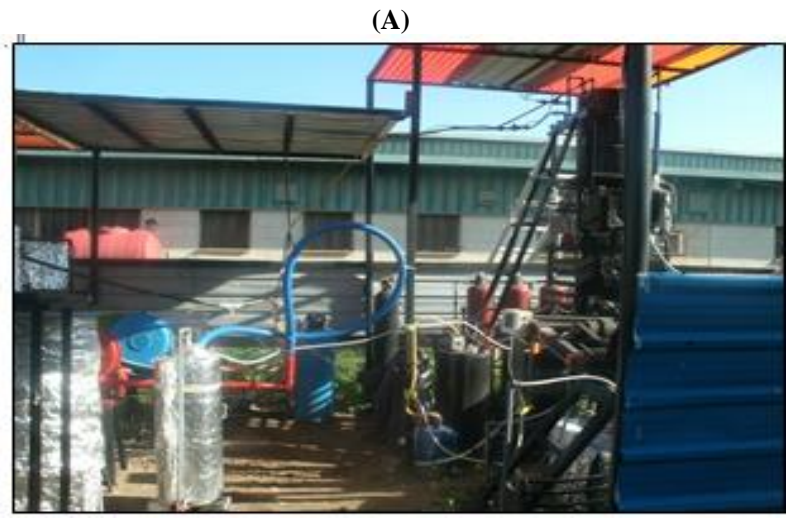

(B)

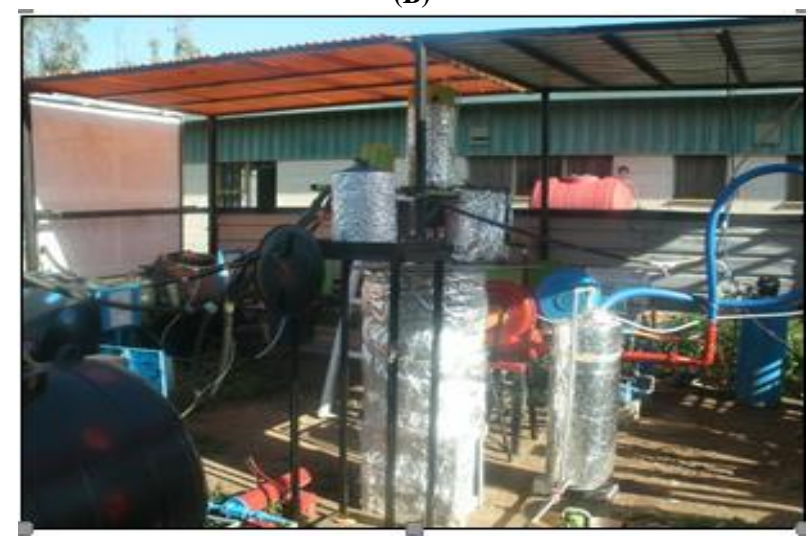

Fig. 1: (A, B) the Text System of Adsorption Materials and Tanks of AlMasaya Industrial Water.

\section{Result and discussion}

\subsection{The results of atomic absorption spectrometer de- vice (aa-6300)}

Samples were analyzed using a spectrometer of atomic absorption (AA-6300). Device technology based on the principle of absorption spectroscopy to determine the concentration of the sample depending on the extent of radiation absorbed. Operation based on the absorption wavelength and that is unique to each element of the metallic elements, heavy soluble as well as lower photometric at that wavelength, and based on that determines the concentration of the element under test. Atomic absorption spectroscopy (AA6300) see in Fig.2, spectroscope test results before and after treatment and absorbent material can be seen through the Fig. 3.



Fig. 2: Atomic Absorption Spectrometer Device (AA-6300).

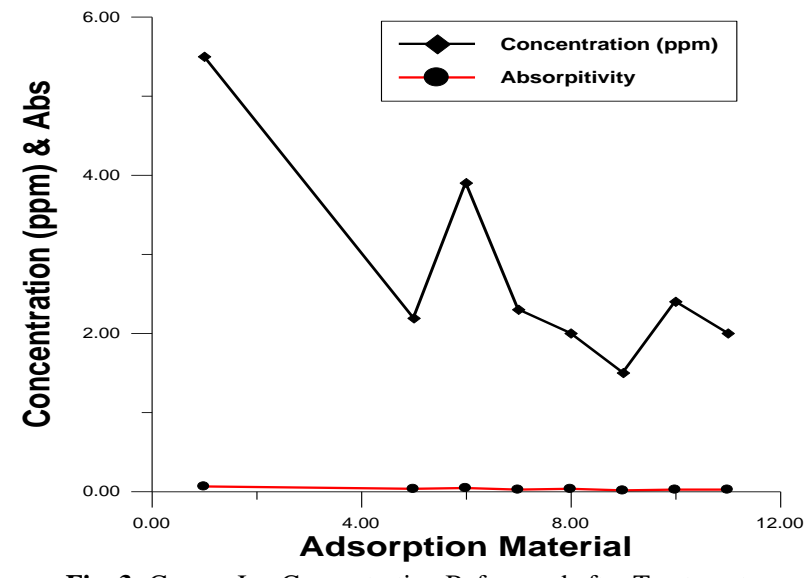

Fig. 3: Copper Ion Concentration Before and after Treatment.

\subsection{Results of matching between practical and theoreti- cal models}

Design of multi stages for this system produced clean water without free radicals soluble ions by more than $(73 \%)$ as shown in Fig. 3 above, this percent is due to optimal use of the total equipment's which operated efficiently. Powders used are treated inside the furnace, carbon dioxide used in the oven at high temperatures to eliminate the substances that inhibit pores interfaces between molecules during the carbonization process, so that the pores are three activation processes depends on the time required to stay, whenever stay long time inside the oven was, the great size of pores formed. Nitrogen supplied inside oven to isolate and remove carbon dioxide for reducing harmful emissions ratio, also used to reduce the ratio of carbon combustion inside the furnace. The preference criteria for the selection best filtration materials depends on the number of supported variables on the analytical side of each of (Freundlich and Langmuir models), when thermal content $(\Delta \mathrm{G})$ is more negative, shape of isotherm is a value between one and zero, and enthalpy value was positive, the elected choice is the best among many working choices, when the inverse ability absorbance is the least, and the logarithm of equilibrium state is the highest, Langmuir constant is the highest the choice is the best also among many working choices, we see also from calculations that when maximum capacity is the highest, inverse of maximum capacity is at least, the choice is the better. Practical tests show that the Green Algae powder is the best efficient adsorbent materials with an efficiency equals to (77\%) as shown in Fig.4 and Tables $(6,8$, and 9), this material also show a lower thermal coefficient as shown in Fig. 7, also seen less Gips free energy as shown in Fig. 5. Pulp date powder has proven to be excellent efficiency $(75 \%)$ with enthalpy equals to $(-12 \mathrm{~kJ} / \mathrm{mol})$.Mathematical model of (Freundlich), Langmuir, and thermodynamic specification for (Pulp date powder) is shown in Table (1). Mathematical model of Freundlich, Langmuir, and thermodynamic specification for (Garlic powder) shown in Table (2).Mathematical model of Freundlich, Langmuir, and thermodynamic specifications for (Alfalfa leaf powder) is shown in Table (3). Mathematical model of Freundlich, Langmuir, and thermodynamic specifications for (Seder tree powder) is shown in Table (4). Mathematical model of Freundlich, Langmuir, and thermodynamic specifications for (Calptoze tree powder) is shown Table (5). Mathematical model of Freundlich, Langmuir, and thermodynamic specifications for (Green Algae powder) is shown in Table (6). Mathematical model of Freundlich, Langmuir, and thermodynamic specifications for (Mixture of onion juice powder) is shown in Table (7). Comparison between (1/Qe, Log Qe, Log Ce) of adsorbent materials is shown in Fig. Comparison between Gips free energy, enthalpy, and entropy of adsorbent materials is shown in Fig.6. Comparison between Kl, RI of adsorbent materials as shown in Fig.7. 


\subsection{Results of mathematical model variables (Freun- dlich and Langmuir)}

The results show full conformity between empirical variables and calculations of the mathematical models which demonstrates the validity of experience from both theoretical and practical, also the results show full compatibility with the results of other researchers in case of addition aqueous solution experiments. The two models and thermodynamic specifications are as shown below:

Table 1: Mathematical Model of (Freundlich), Langmuir, and Thermodynamic Specification of (Pulp Date Powder) For Adsorption the Free Radicals for Copper Ions at (313 Kelvin)

\begin{tabular}{lll}
\hline Freundlich model & & \\
\hline Variable & Value & Symbol \\
Removal Efficiency & $75 \%$ & $\mathrm{RE}$ \\
Equilibrium Adsorption Capacity & $1.6(\mathrm{mg} / \mathrm{g})$ & $\mathrm{Qe}$ \\
Equilibrium Constant & 1.9 & $\mathrm{Kf}$ \\
Inverse of Equilibrium Capacity & $0.62(\mathrm{~g} / \mathrm{mg})$ & $1 / \mathrm{Qe}$ \\
Logarithm of (Qe) & 0.2 & $\mathrm{Log}$ \\
Equilibrium Concentration & $2.5(\mathrm{mg} / \mathrm{l})$ & $\mathrm{Qe})$ \\
Logarithm of equilibrium Concentration & 0.39 & $\mathrm{Leg} \mathrm{Ce}$ \\
Initial Concentration & $5.7(\mathrm{mg} / \mathrm{l})$ & $\mathrm{Ci}$ \\
Inverse of Slope & 0.7 & $\mathrm{n}$ \\
Langmuir model & & \\
Langmuir Constant & 0.45 & $\mathrm{Kl}$ \\
Shape of Isotherm 0<R<1 & 0.3 & $\mathrm{Rl}$ \\
Maximum Absorbent capacity (mg/g) & 2.9 & $\mathrm{Qm}$ \\
Inverse of Maximum Capacity & 0.344 & $1 / \mathrm{Qm}$ \\
Logarithm of Maximum Capacity & 0.4 & $\mathrm{Log} \mathrm{Qm}$ \\
Thermodynamic specification & & \\
Gips Free energy(KJ/mole)/ The best is the & -12 & $\mathrm{G} \Delta$ \\
more negative & 14 & $\mathrm{H} \Delta$ \\
Enthalpy(KJ/mole)/ Endothermic processes & 14 & $\mathrm{~S} \Delta$ \\
Entropy(KJ/mole)/ Reaction by itself & 39 & \\
\hline
\end{tabular}

Table 2: Mathematical Model of (Freundlich), Langmuir, and Thermodynamic Specification of (Garlic Powder) For Adsorption the Free Radicals for Copper Ions at (313 Kelvin)

Freundlich model

\begin{tabular}{|c|c|c|}
\hline Variable & Value & Symbol \\
\hline Removal Efficiency & $68 \%$ & RE \\
\hline Equilibrium Adsorption Capacity & 1.89 & Qe (mg/gm) \\
\hline Equilibrium Constant & 1.7 & $\mathrm{Kf}$ \\
\hline Inverse of Equilibrium Capacity & 0.55 & 1/Qe \\
\hline Logarithm of (Qe) & 0.25 & $\log (\mathrm{Qe})$ \\
\hline Equilibrium Concentration & 2.4 & $\mathrm{Ce}(\mathrm{mg} / \mathrm{l})$ \\
\hline Logarithm of equilibrium Concentration & 0.33 & $\log \mathrm{Ce}$ \\
\hline Initial Concentration & 0.4 & $\mathrm{Ci}(\mathrm{mg} / \mathrm{l})$ \\
\hline Inverse of Slope & 0.35 & $\mathrm{n}$ \\
\hline \multicolumn{3}{|l|}{ Langmuir model } \\
\hline Langmuir Constant & 0.51 & $\mathrm{~K} 1$ \\
\hline Shape of Isotherm $0<R<1$ & 0.29 & Rl \\
\hline Maximum Absorbent capacity (mg/g) & 3 & Qm \\
\hline Inverse of Maximum Capacity & 0.3 & $1 / \mathrm{Qm}$ \\
\hline Logarithm of Maximum Capacity & 0.47 & $\log \mathrm{Qm}$ \\
\hline \multicolumn{3}{|l|}{ Thermodynamic specification } \\
\hline \multicolumn{2}{|c|}{$\begin{array}{l}\text { Gips Free energy }(\mathrm{KJ} / \mathrm{mole}) / \text { The best is the }-15 \\
\text { more negative }\end{array}$} & $\mathrm{G} \Delta$ \\
\hline Enthalpy $(\mathrm{KJ} / \mathrm{mole}) /$ Endothermic processes & 33 & $\mathrm{H} \Delta$ \\
\hline Entropy $(\mathrm{KJ} / \mathrm{mole}) /$ Reaction by itself & 49 & $\mathrm{~S} \Delta$ \\
\hline
\end{tabular}

Table 3: Mathematical Model of (Freundlich), Langmuir, and Thermodynamic Specification of (Alfalfa Leaf Powder) For Adsorption the Free Radicals for Copper Ions at (313 Kelvin).

\begin{tabular}{lll}
\hline Freundlich model & & \\
\hline Variable & Value & Symbol \\
Removal Efficiency & $40 \%$ & $\mathrm{RE}$ \\
Equilibrium Adsorption Capacity & 0.7 & $\mathrm{Qe}(\mathrm{g} / \mathrm{mg})$ \\
Equilibrium Constant & 0.5 & $\mathrm{Kf}$ \\
Inverse of Equilibrium Capacity & 1.4 & $1 / \mathrm{Qe}$ \\
Logarithm of (Qe) & 0.15 & $\mathrm{Log}(\mathrm{Qe})$ \\
Equilibrium Concentration & 4 & $\mathrm{Ce}(\mathrm{mg} / \mathrm{l})$ \\
Logarithm of equilibrium Concentration & 0.6 & $\mathrm{Log} \mathrm{Ce}$ \\
Initial Concentration & 5.8 & $\mathrm{Ci}(\mathrm{mg} / \mathrm{l})$ \\
Inverse of Slope & 0.6 & $\mathrm{n}$ \\
Langmuir model & & \\
Langmuir Constant & 0.28 & $\mathrm{Kl}$ \\
Shape of Isotherm 0<R<1 & 0.47 & $\mathrm{Rl}$ \\
Maximum Absorbent capacity (mg/g) & 1.6 & $\mathrm{Qm}$ \\
Inverse of Maximum Capacity & 0.6 & $1 / \mathrm{Qm}$ \\
Logarithm of Maximum Capacity & 0.2 & $\mathrm{Log} \mathrm{Qm}$ \\
Thermodynamic specification & & \\
Gips Free energy(KJ/mole)/ The best is the more & -7 & $\mathrm{G} \Delta$ \\
negative & & $\mathrm{H} \Delta$ \\
Enthalpy(KJ/mole)/ Endothermic processes & 9 & $\mathrm{~S} \Delta$ \\
Entropy(KJ/mole)/ Reaction by itself & 13 & \\
\hline
\end{tabular}

Table 4: Mathematical Model of (Freundlich), Langmuir, and Thermodynamic Specification of (Seder Tree Powder) For Adsorption the Free Radicals for Copper Ions at (313 Kelvin)

\begin{tabular}{lll}
\hline Freundlich model & & \\
\hline Variable & Value & Symbol \\
Removal Efficiency & $45 \%$ & $\mathrm{RE}$ \\
Equilibrium Adsorption Capacity & 1.4 & $\mathrm{Qe}$ \\
Equilibrium Constant & 1.41 & $\mathrm{Kf}$ \\
Inverse of Equilibrium Capacity & 1.71 & $1 / \mathrm{Qe}$ \\
Logarithm of (Qe) & 0.3 & $\mathrm{Log}$ \\
Equilibrium Concentration & 2.3 & $\mathrm{Ce}$ \\
Logarithm of equilibrium Concentration & 0.14 & $\mathrm{Log}$ Ce \\
Initial Concentration & 5,8 & $\mathrm{Ci}$ \\
Inverse of Slope & 0.6 & $\mathrm{n}$ \\
Langmuir model & & \\
Langmuir Constant & 0.48 & $\mathrm{~K} 1$ \\
Shape of Isotherm 0<R<1 & 0.31 & $\mathrm{Rl}$ \\
Maximum Absorbent capacity (mg/g) & 2.8 & $\mathrm{Qm}$ \\
Inverse of Maximum Capacity & 0.35 & $1 / \mathrm{Qm}$ \\
Logarithm of Maximum Capacity & 0.44 & $\mathrm{Log} \mathrm{Qm}$ \\
Thermodynamic specification & & \\
Gips Free energy(KJ/mole)/ The best is the more & -13 & $\mathrm{G} \Delta$ \\
negative & & $\mathrm{H} \Delta$ \\
Enthalpy(KJ/mole)/ Endothermic processes & 25 & $\mathrm{~S} \Delta$ \\
Entropy(KJ/mole)/ Reaction by itself & 38 &
\end{tabular}

Table 5: Mathematical Model of (Freundlich), Langmuir, and Thermodynamic Specification of (Calptoze Tree Powder) For Adsorption the Free Radicals for Copper Ions at (313 Kelvin)

\begin{tabular}{lll}
\hline Freundlich model & & \\
\hline Variable & Value & Symbol \\
Removal Efficiency & $06 \%$ & $\mathrm{RE}$ \\
Equilibrium Adsorption Capacity & 1.8 & $\mathrm{Qe}$ \\
Equilibrium Constant & 2.8 & $\mathrm{Kf}$ \\
Inverse of Equilibrium Capacity & 0,5 & $1 / \mathrm{Qe}$ \\
Logarithm of (Qe) & 0.25 & $\mathrm{Log}$ \\
Equilibrium Concentration & 1.8 & $\mathrm{Ce})$ \\
Logarithm of equilibrium Concentration & 0.25 & $\mathrm{Log} \mathrm{Ce}$ \\
Initial Concentration & 5.7 & $\mathrm{Ci}$ \\
Inverse of Slope & 0.08 & $\mathrm{n}$ \\
Langmuir model & & \\
Langmuir Constant & 0.8 & $\mathrm{Kl}$ \\
Shape of Isotherm 0<R<1 & 0.3 & $\mathrm{Rl}$ \\
Maximum Absorbent capacity (mg/g) & 3.5 & $\mathrm{Qm}$ \\
Inverse of Maximum Capacity & 0.28 & $1 / \mathrm{Qm}$ \\
Logarithm of Maximum Capacity & 0.5 & $\mathrm{Log} \mathrm{Qm}$ \\
Thermodynamic specification & & \\
Gips Free energy(KJ/mole)/ The best is the more & -36 & $\mathrm{G} \Delta$ \\
negative & 78 & $\mathrm{H} \Delta$ \\
Enthalpy(KJ/mole)/ Endothermic processes & 111 & $\mathrm{~S} \Delta$ \\
Entropy(KJ/mole)/ Reaction by itself & & \\
\hline
\end{tabular}


Table 6: Mathematical Model of (Freundlich), Langmuir, and Thermodynamic Specification of (Green Algae Powder) For Adsorption the Free Radicals for Copper Ions at (313 Kelvin)

\begin{tabular}{lll}
\hline Freundlich model & & \\
\hline Variable & Value & Symbol \\
Removal Efficiency & $77 \%$ & $\mathrm{RE}$ \\
Equilibrium Adsorption Capacity & 2 & $\mathrm{Qe}$ \\
Equilibrium Constant & 1.8 & $\mathrm{Kf}$ \\
Inverse of Equilibrium Capacity & 0.5 & $1 / \mathrm{Qe}$ \\
Logarithm of (Qe) & 0.3 & $\mathrm{Log}$ \\
Equilibrium Concentration & 2.9 & $\mathrm{Ce}$ \\
Logarithm of equilibrium Concentration & 0.46 & $\mathrm{Log} \mathrm{Ce}$ \\
Initial Concentration & 6 & $\mathrm{Ci}$ \\
Inverse of Slope & 00.7 & $\mathrm{n}$ \\
Langmuir model & & \\
Langmuir Constant & 0.9 & $\mathrm{Kl}$ \\
Shape of Isotherm 0<R<1 & 0.4 & $\mathrm{Rl}$ \\
Maximum Absorbent capacity (mg/g) & 3.8 & $\mathrm{Qm}$ \\
Inverse of Maximum Capacity & 0.26 & $1 / \mathrm{Qm}$ \\
Logarithm of Maximum Capacity & 0.57 & $\mathrm{Log} \mathrm{Qm}$ \\
Thermodynamic specification & & \\
Gips Free energy(KJ/mole)/ The best is the more & -39 & $\mathrm{G} \Delta$ \\
negative & 78 & $\mathrm{H} \Delta$ \\
Enthalpy(KJ/mole)/ Endothermic processes & 113 & $\mathrm{~S} \Delta$ \\
Entropy(KJ/mole)/ Reaction by itself & & \\
\hline
\end{tabular}

Table 7: Mathematical Model of (Freundlich), Langmuir, and Thermodynamic Specification of (Mixture of Onion Juice Powder) for Adsorption the Free Radicals for Copper Ions at (313 Kelvin)

\begin{tabular}{lll}
\hline Freundlich model & & \\
\hline Variable & Value & Symbol \\
Removal Efficiency & $68 \%$ & $\mathrm{RE}$ \\
Equilibrium Adsorption Capacity & 1.8 & $\mathrm{Qe}$ \\
Equilibrium Constant & 1.9 & $\mathrm{Kf}$ \\
Inverse of Equilibrium Capacity & 0.5 & $1 / \mathrm{Qe}$ \\
Logarithm of (Qe) & .02 & $\mathrm{Log}$ \\
Equilibrium Concentration & 2.1 & $\mathrm{Ce}$ \\
Logarithm of equilibrium Concentration & 0.32 & $\mathrm{Log}$ Ce \\
Initial Concentration & 5.7 & $\mathrm{Ci}$ \\
Inverse of Slope & 03.9 & $\mathrm{n}$ \\
Langmuir model & & \\
Langmuir Constant & 0.54 & $\mathrm{~K} 1$ \\
Shape of Isotherm 0<R<1 & 0.32 & $\mathrm{Rl}$ \\
Maximum Absorbent capacity (mg/g) & 2.9 & $\mathrm{Qm}$ \\
Inverse of Maximum Capacity & 0.34 & $1 / \mathrm{Qm}$ \\
Logarithm of Maximum Capacity & 0.46 & $\mathrm{Log} \mathrm{Qm}$ \\
Thermodynamic specification & & \\
Gips Free energy(KJ/mole)/ The best is the more & -18 & $\mathrm{G} \Delta$ \\
negative & 38 & $\mathrm{H} \Delta$ \\
Enthalpy(KJ/mole)/ Endothermic processes & 50 & $\mathrm{~S} \Delta$ \\
Entropy(KJ/mole)/ Reaction by itself & & \\
\hline
\end{tabular}

Table 8: Comparison between Absorbent Materials Specifications at a Temperature (313 Kelvin), Liquid Volume at Final Test Equal to (1 Liter), Weight of the Adsorbent Material Is (250g)

\begin{tabular}{llllllllll}
\hline Material & Efficiency & 1/Qe & Log Qe & Log Ce & Gips & Enth. Entr. KL & RI \\
\hline 1 & 75 & 0.62 & 0.2 & 0.39 & -12 & 41 & 39 & 0.45 & 0.31 \\
2 & 68 & 0.55 & 0.25 & 0.33 & -15 & 33 & 49 & 0.51 & 0.29 \\
3 & 40 & 1.4 & 0.15 & 0.6 & -7 & 9 & 13 & 0.28 & 0.47 \\
4 & 45 & 1.71 & 0.3 & 0.14 & -13 & 25 & 38 & 0.48 & 0.31 \\
5 & 60 & 0.51 & 0.25 & 0.25 & -36 & 78 & 111 & 0.8 & 0.3 \\
6 & 77 & 0.5 & 0.3 & 0.46 & -39 & 78 & 113 & 0.9 & 0.4 \\
7 & 68 & 0.5 & 0.2 & 0.32 & -18 & 38 & 50 & 0.54 & 0.32 \\
\hline
\end{tabular}

Table 9: Comparison between Absorbent Materials Efficiency, Gips Free Energy, and Thermal Coefficient at a Temperature (313 Kelvin), Liquidvolume at Final Test Equal to (1 Liter), Weight of the Adsorbent Material Is (250g)

\begin{tabular}{llll}
\hline $\begin{array}{l}\text { Gips free energy } \\
(\mathrm{KJ} / \mathrm{mole}-\mathrm{E})\end{array}$ & $\begin{array}{l}\text { Thermal coefficient } \\
(\mathrm{RL})<10<\mathrm{R}\end{array}$ & $\begin{array}{l}\text { Efficiency } \\
(\zeta \%)\end{array}$ & Material \\
\hline-12 & 0.3 & 75 & $\begin{array}{l}\text { Pulp date powder } \\
(1)\end{array}$ \\
-15 & 0.29 & 68 & $\begin{array}{l}\text { Garlic powder }(2) \\
\text { Alfalfa leaf powder } \\
-7\end{array}$ \\
0.47 & 40 & $\begin{array}{l}(3) \\
\text { Seder tree powder } \\
(4)\end{array}$ \\
-13 & 0.31 & 45 & $\begin{array}{l}\text { Calptoze tree pow- } \\
\text { der }(5)\end{array}$ \\
-36 & 0.3 & 60 & $\begin{array}{l}\text { Green Algae pow- } \\
\text { der }(6) \\
\text { Mixture of onion } \\
\text { powder }(7)\end{array}$ \\
\hline
\end{tabular}

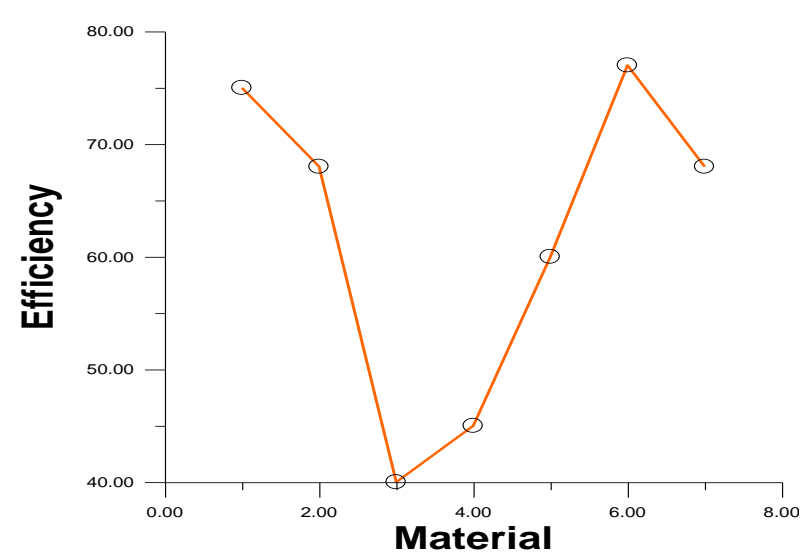

Fig. 4: Comparison between Adsorbent Materials Efficiencies.

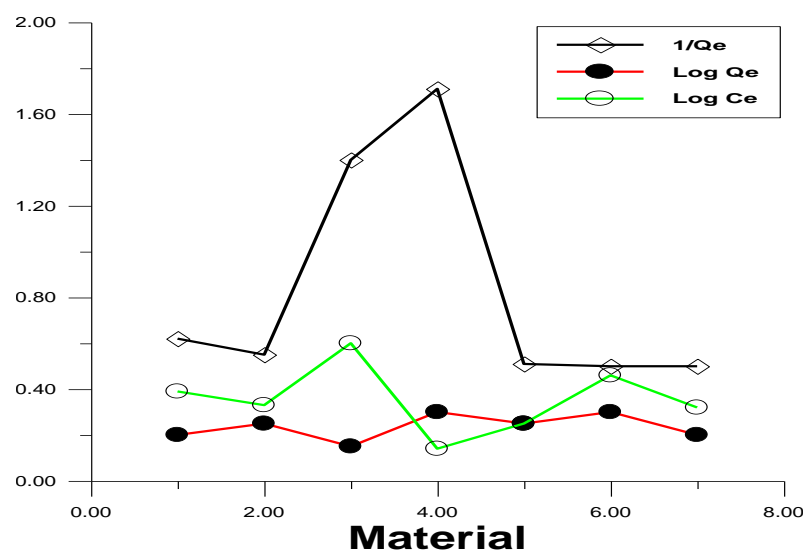

Fig. 5: Comparison between (1/Qe, Log Qe, Log Ce) Adsorbent Materials of.

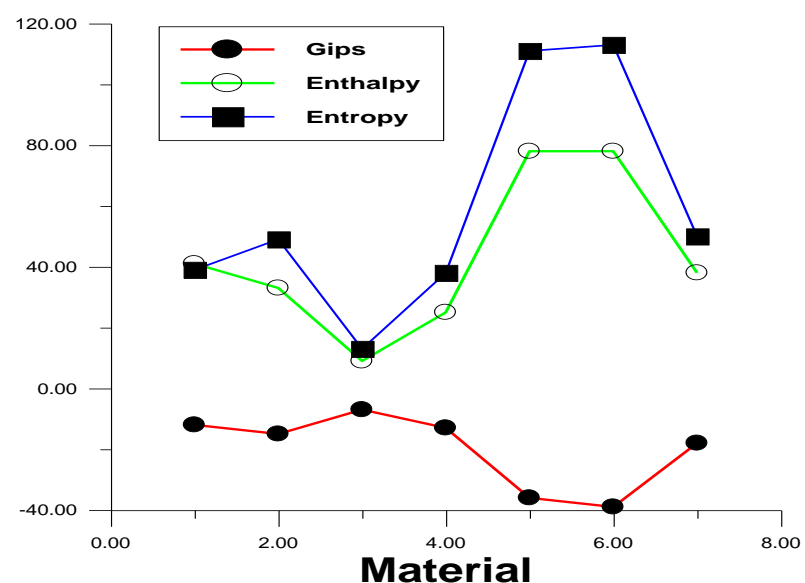

Fig. 6: Comparison between Gips Free Energy, Enthalpy, and Entropy. 


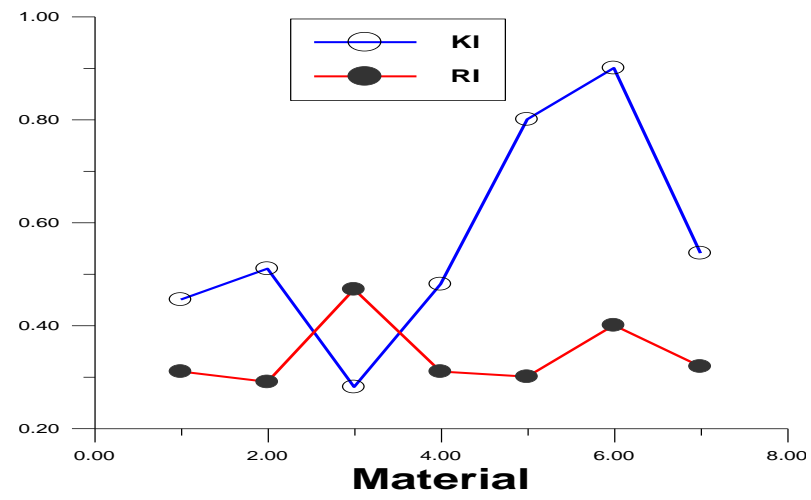

Fig. 7: Comparison between Kl, RI of Adsorbent Materials.

\subsection{Results of bacterial and viruses tests}

Random samples were taken from multiple treatment samples at a rate equal to $(0.5$ liter $)$ for each sample of the test samples to the biological lab of University. The researcher aimed from this work to check the water content, and the extent of it is free from viruses and bacteria. The results provided from the treatment water proved the water free from any contaminants or bacterial Viruses after different treatment processes. The reason for this is due to the extreme case of heating and the impact of hot steam through the various stages of treatment. Devices used as shown in Fig. 8.

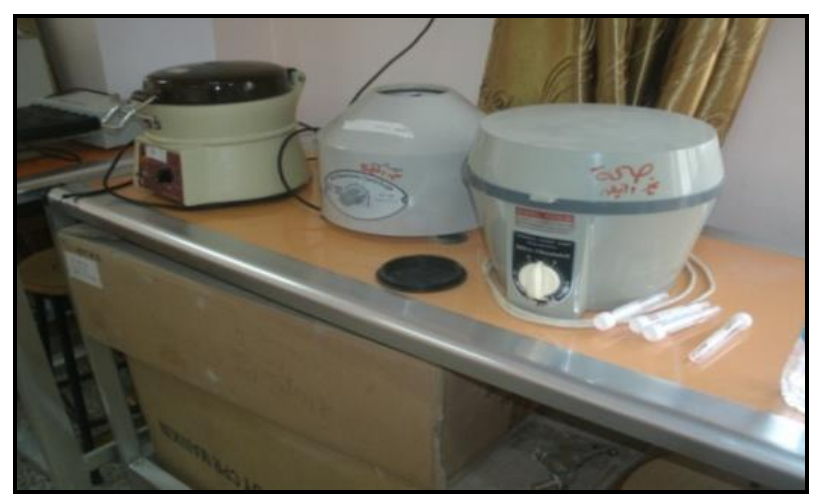

Fig. 8: Devices Used In Biological Testes.

\section{Conclusion}

All testes did, proved that there is an exact match between the empirical processes and results of mathematical modelling calculations, this know through the mathematical analysis of the trial data under different temperatures. Matching results with the models of (Langmuir \&Freundlich) proved that the green algae powder is the best filtered material, because its high adsorption efficiency which equal to $(77 \%)$ with Gips free energy equal to $(-39$ $\mathrm{kJ} / \mathrm{mol}$ ).Pulp date powder has proven to be excellent efficiency $(75 \%)$ with enthalpy equals to $(-12 \mathrm{~kJ} / \mathrm{mol})$. All Adsorbent materials have coefficient of thermal located between (zero $<R<1$ ), so this value represents the perfect choice to be test at this system. All food remnants choices have been tested in our ion adsorbed design system.

\section{References}

[1] Ruthven, D.," Principle of Adsorption and Adsorption Process", New York: John wiley and sons, 1984.

[2] Sugumaran, P., Priya Susan. V, Ravichandran. P., Seshadri. S.," Production and Characterization of Activated Carbon from Banana Empty Fruit Bunch and Delonixregia Fruit Pod. Journal of Sustainable Energy \& Environment, pp. 125-132, 2012.

[3] Tsai. W, Chang. C,.Wang. S,.Chhien.S, Sun.H.," Preparation of activated carbons from corn cob catalyzedby potassium salts and subsequent gasification with CO2", Bioresorcer Technology, pp. 203$208,2012$.
[4] Zoey, Han.B," High-Surface-Area Activated Carbon from Chinese Coal", Energy Fuels, pp. 1383-1386, 2001.

[5] Anjalikoli. M., "Preliminary studies on the adsorption behavior of chromium on fly ash", Chemical Engineering, World. XXXII, pp. 81-82, 1997.

[6] Ganzerli. M, Magge. L, Caramella. V.," Characterization of lead Rhodizonate as Barium and Radium adsorber from fresh-water adsorption-behavior of earth alkaline ions", Nucl.Chem, pp.109-113, 1997.

[7] Koffman. R, Stringer. J, Feinberg. R, Goldfrank. L," Comparative efficacy of thallium adsorption by activated charcoal, brussian blue, and sodium polystyrene sulfonate", J-Toxical-Clin-Toxicol, pp. 833, 1999.

[8] Kartel .M, Kupchik. L, Veisov. B," Evaluation of pectin binding of heavy metal ions in aqueous solutions", Chemosphere, 38(11) 2591-6, 1999.

[9] Prodhan. AA, Levine.AD," Microbial biosorption of copper and lead form aqueous system", Sci.Total-Environment. 17(3): 209-20, 1995.

[10] hoglu. Y, Malkoc. E, Gurses. A, Canpolat. N.," The removal of $\mathrm{Cu}$ (II) from aqueous solutions by Ulothrixzonata",Bioresour Technol. 85(3):331-3, 2002.

[11] Ferguson. LR, Harris.PJ. ," Studies on the role of specific dietary fibers in protection against colorectal cancer", Mutat-Res, 19; 350(1) - 173-84, 1996.

[12] Adachi. A, Takagi. S, Okano. T.," Studies on Removal Efficiency of Rice Bran for Pesticides", J. Health Sci, 47(2): 94-98, 2001.

[13] Hameed. B, Rahman. A.," Removal of phenol from aqueous Solution by Adsorption onto Activated Carbon Prepared from Biomass Material", Applied science publishers LTD, Essex, chapter 3, pp. 49-84, 2008.

[14] Karwi, Abbas Ali Mahmood, "Use of Detectors Technology for Gamma Ray Issued from Radioactive Isotopes and its Impact on Knowledge of Behavior of the Stationary Case of Solid Phase Holdup", World Academy of Science, Engineering and Technology, 2012.

[15] Karwi, Abbas Ali Mahmood, "Alignment of Emission Gamma Ray Sources with Nai(Ti) Scintillation Detectors by Two Laser Beams to Pre-Operation using Alternating Minimization Technique", World Academy of Science, Engineering and Technology, 2012.

[16] Karwi, Abbas Ali Mahmood, "Image of Multi Phase Phantoms Using Alternating Minimization Algorithm in Noninvasive Measurement Technique", Journal of Communication and Computer 9, 1269-1278, 2012.

[17] Karwi, Abbas Ali Mahmood, Abdullah Eman Mohammed, "Shielding Processing Technique through the Calculations and Measurement of the Time Averaged Cross-Section of Multiphase Domain", Global Journal of Researches in Engineering, Volume 12 Issue 3 Version 1.0, ISSN: 2249-4596 \& Print ISSN: 0975-5861, 2012.

[18] Karwi, Abbas Ali Mahmood, " Design System to Adsorb Soluble Metallic Ions Using Biomass Materials To Maintain The Safety and stability of The saturated Liquids", Kufa Journal of Engineering Vol. 9, No. 1, January 2018, PP. 91-105 Received 21 February 2017, accepted 8, May 2017.

[19] Karwi, Abbas Ali Mahmood, Eman Mohammed Abdullah," Empirical Study Heating Processes Effect on the Decay of Irradiation Radon Gas Products and Calculation the Optimal Benefit Cost", International Journal of Engineering Innovation \& Research Volume 4, Issue 3, ISSN: $2277-5668$.

[20] Karwi, Abbas Ali Mahmood, "Preparation Radioactive Particle Technique Used To Track the Motion of Oil Phase in High Pressure Tank", International Journal of Electronics Communication and Computer Engineering Volume 3, Issue 6, ISSN (Online): 2249071X, ISSN (Print): 2278-4209.

[21] Karwi, Abbas Ali Mahmood," The Negative Harmful Effects of High Irradiation Gas Concentration Treated By Facility Designed and Use the Model of an Accounting Disclosure", International Journal of Research in Engineering and Social Sciences, ISSN 2249-9482, Impact Factor: 6.301, Volume 07 Issue 1, January, Page $1-13,2017$.

[22] Karwi, Abbas Ali Mahmood, Eman Mohammed Abdullah, "Computed Tomography Used in Petroleum for Imaging Oil Phase during Runoff', MPC, the Twelfth Mediterranean Petroleum Conference and Exhibition, 2012.

[23] Abdullh, E.M, Modeling Cost Structure for Assessment Production Cost of Algal - Biofuel, World Academy of Science, Engineering and Technology International Journal of Mathematical, Computational, Physical, Electrical and Computer Engineering, WASET, M ADRID, SPAIN, 2012 